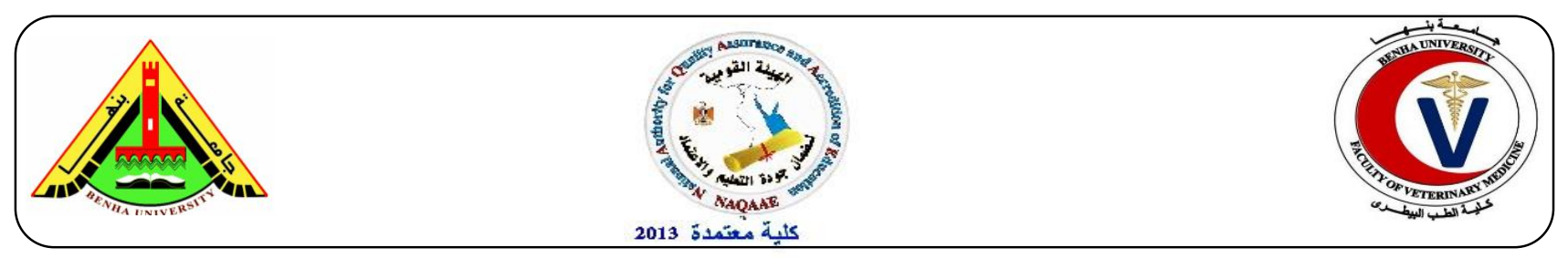

\title{
Teratogenic Effect of Meloxicam on Pregnant Rats: Implication of Organogenesis Period
}

\author{
${ }^{2}$ Elkomy A.A, ${ }^{2}$ Mohammed. S. Abo Salem M.S., ${ }^{1}$ Asmaa M. Kandeil A.M., ${ }^{1}$ A. Hassan \\ W.A., ${ }^{1}$ Elhemiely A.A. \\ ${ }^{1}$ National Organization for Drug Control and Research (NODCAR), Egypt \\ ${ }^{2}$ Faculty of Veterinary Medicine Banha University, Egypt
}

\section{A B S T R A C T}

This study was carried out to detect the risk of meloxicam use on fetuses. It was given to pregnant rats orally by dose 1.35 and $2.70 \mathrm{mg} / \mathrm{kg}$ b.wt, from $6^{\text {th }}$ day until the $15^{\text {th }}$ day of gestation daily. At $20^{\text {th }}$ day of gestation female sacrified; morphological, visceral, skeletal, biochemical and histopathological studies were carried out to evaluate its harmful effect. Meloxicam increased abortion rate and fetal resorptions as well as growth retardation and external malformations as hematoma and paralysis of limbs. Visceral examination showed defects in internal organs. Weak and incomplete ossification in axial and appendicular system were observed by skeletal examination. Drug caused increased level of MDA meanwhile reduction of glutathione reduced in liver tissue of fetuses. The histopathological examination revealed presence of marked degenerative changes in liver and kidney of fetuses. This study support and proof the potential risks of the Meloxicam administration on fetuses.

Key words: Rats, pregnancy, Meloxicam, NSAIDS.

(http://www.bvmj.bu.edu.eg)

(BVMJ-35(2): 317-327, 2018)

\section{INTRODUCTION}

Experiments performed in the field of teratology led to the discovery of a great number of teratogenic agents that produce congenital malformations. Several types of drugs, which may be used during pregnancy, have been found to induce teratogenicity in human and laboratory animals (Schardein, 1977).

Meloxicam is non-steroidal antiinflammatory drug (NSAID) which provide analgesia and suppress inflammation by inhibiting the enzyme cyclooxygenase, resulting in decreased prostaglandin synthesis (Urban, 2000).NSAIDs are among the most common drugs prescribed to pregnant women to treat fever, pain and inflammation (Qstensen and skomsroll, 2004). NSAIDs when given to pregnant women cross the placenta and may cause embryo and fetal adverse effects, Exposure to NSAIDs associated with an increased risk of premature closure of the fetal ductus arteriosus and oligohydramnios. Fetal adverse effects affecting the brain, kidney, lung, skeleton, gastrointestinal tract and cardiovascular system have also been reported after prenatal exposure to NSAIDs (Antonucci et al., 2012). Administration of NSAIDs has occasionally 
been related to fetal and neonatal cardiopulmonary, gastrointestinal, cerebral and renal complications.

This report described a term newborn with severe persistent pulmonary hypertension due to premature closure of the ductus arteriosus following a 5 day maternal treatment with diclofenac two weeks before delivery (Zenker et al., 1998 ). Previous studies recorded that Meloxicam exhibited potential effect on implantation and parturition processes of pregnant rats as number of implantation sites was significantly decreased whereas the number of resorption sites were significantly increased (Sahar et al., 2006). On early stage chicken embryo, the application of meloxicam in high doses causes retardation in general embryonic progress and further retardation in the development of the neural system which ends in an open neural tube (Ahmet et al., 2010).Use of NSAIDs during pregnancy is grossly underestimated by maternal history; and is significantly associated with persistent pulmonary hypertension.

So the aim of the persent work is to detect the teratogenic effect of meloxicam .

\section{MATERIALS AND METHODS}

\subsection{Drug}

It is a white powder insoluble in water. Meloxicam was obtained as a pure sample purchased from Adwia co., Cairo, Egypt. 2.2.Animals

Adult Sprague-Dawley female rats 11-13 weeks were used in this study. They were got from the breeding colony then maintained at the animal house of the National Organization for Drug Control and Research (NODCAR, Giza, Egypt). Animals were caged in four groups, given suitable food and water was allowed ad libitum. Animals were subjected to an adaptation period of 2 weeks in the animal house before experiments. They were maintained at $21-24^{\circ} \mathrm{C}$ and $40-60 \%$ relative humidity with 12-h light-dark cycle. Experimental procedures were conducted in accordance with the ethical guidelines for investigations in laboratory animals and were approved by the Research Ethical Committee of Faculty of Pharmacy, Cairo University (Cairo, Egypt) to comply with the Guide for the Care and Use of Laboratory Animals (Institute of Laboratory Animal Resources 1996).

To select the female with regular estrus, for 5 days vaginal smears were prepared every morning and examined under the light microscope. Presence of spermatozoa in the obtained vaginal smear indicates day zero of pregnancy (Barcellona et al., 1977). So each two females were paired with a male of proven fertility in a separate cage overnight. In the next morning, a vaginal smear was taken to confirm the first day of pregnancy.

2.3. Experimental design and sampling

In this study, 44 pregnant rats were used and randomly divided into four groups (each group contain 10 animals except double therapeutic dose group which contain 14 animals). The experimental groups were as follows: Group 1(normal control group) received the ordinary drinking water, Group 2 (tween 80 group) received $1 \mathrm{ml}$ of $2 \%$ Tween 80 as a vehicle, Group3 received Meloxicam in dose $1.35 \mathrm{mg} / \mathrm{kg}$ b.wt (therapeutic dose) and Group 4 received Meloxicam in dose 2.70 $\mathrm{mg} / \mathrm{kg}$ b.wt. (double therapeutic dose )modified human doses (Paget and Barnes 1964).

The doses of drug in the treatment Groups was defined according to the weights of the rats. Moreover, the drug dose was adjusted accordingly. The control solutions and drug were administered orally, daily from $6^{\text {th }}$ until $15^{\text {th }}$ day of gestation via gastric tube. Water and food were supplied ad libitum during all 2.3.1. the experiment.

Developmental observations At the $20^{\text {th }}$ day of gestation female were 
sacrificed. Abortion, resorptions, fetal body weight, body length, external malformation, were recorded.

\subsubsection{Visceral examination}

The fetuses were preserved in Bouin's fixative solution then they rinsed with cold water and examined grossly using magnifying lens. Several transverse sections were made throughout the fetal body, according to technique described by (Hayes, 1986). All sections were examined on both sides under a dissecting microscope for any visceral malformations.

\subsubsection{Skeletal staining:}

For skeletal examination, the other fetuses were examined for any skeletal abnormalities using alizarin red stain for fetal bone and alcian blue for cartilage (Inouye, 1976).

Oxidative stress investigation:

Autopsy samples were taken from the liver of mother and fetuses in different groups were stored at $-40^{\circ} \mathrm{C}$ for oxidative stress investigation. Piece of liver were weighted and homogenized in $10 \mathrm{mmol} / \mathrm{L}$ phosphate buffer saline (PBS) as $10 \%(\mathrm{~W} / \mathrm{V})$ at $\mathrm{pH}$ 7.4. The homogenates were centrifuged and the supernatants were taken for the estimation of Glutathione (GSH) reduced and malonaldhyde(MDA) .

\subsubsection{Glutathione Reduced (GSH):}

Tissue GSH was determined by calorimetric method using reagent kits obtained from Bio Diagnostic (Egypt) by the method of (Beutler et al., 1963).

2.3.1.4.Malonaldahyde (MDA):

Lipid peroxidation was determined in liver tissue homogenate by estimating the level of thiobarbituric acid reactive substances (TBARS) measured as MDA. (Uchiyama and Mihara, 1978).

\subsubsection{Histopathological Preparation:}

Liver and kidney of different groups were fixed for histological examination by light microscopy in $10 \%$ formol saline for at least 24 hours and then preserved in $70 \%$ ethyl alcohol.. Serial transverse sections 5 microns thick of different fetuses tissues were cut, mounted and stained with haematoxylin and eosin for general histological studies (Banchroft et al., 1996)

2.4. Statistical analysis:

Results were expressed as mean \pm standard errors of the means (S.E.M). Statistical analysis was performed using the SPSS version 16 (Chicago, IL, USA), while the graphs were drawn using a prism computer program (Graph Pad software Inc. V5, San Diego, CA, USA). Statistical analysis was carried out using $t$ - testes followed by unpaired Test. Probability values of less than 0.05 were considered statistically significant.

\section{RESULTS}

3.1.Effects of meloxicam on rat's fetuses:

\subsubsection{Abortion and resorption}

Data revealed that oral administration of meloxicam in doses of 1.35 and $2.7 \mathrm{mg} / \mathrm{kg}$ b.wt. to pregnant rats from the $6^{\text {th }}$ to the $15^{\text {th }}$ day of gestation caused abortion and early fetal resorption (Table 1-2)

\subsubsection{Growth retardation}

Growth retardation represented by a decrease in fetal body weight and body length observed in the fetuses maternally treated from the $6^{\text {th }}$ to the $15^{\text {th }}$ day of gestation with meloxicam 1.35 and $2.7 \mathrm{mg} / \mathrm{kg}$ (Fig. 1).

\subsubsection{Morphological abnormalities:-}

Some morphological abnormalities as hematoma, paralysis and contraction of limbs noticed in fetuses of pregnant rats treated with meloxicam 1.35 and $2.7 \mathrm{mg} / \mathrm{kg}$ from the 6th to the 15th day of gestation (Fig. 1).

\subsection{Visceral examination of fetuses:-}

Our results showed that Meloxicam use during pergnancy resulted in cerebral dilatation, microcephaly and heamorrage around internal organs by percent when given from the 6th to the 15th day of gestation. (Fig 2). 


\subsection{Skeletal examination}

The skeletal system of control fetuses at the 20th day of gestation showed numerous bony elements stained with alizarin red and few cartilages stained with alcian blue. The main difference between control and maternally treated fetuses is the incomplete ossification of some bones in maternally treated groups.

The administration of doses of 1.35 and 2.70 $\mathrm{mg} / \mathrm{kg}$ meloxicam induced some skeletal anomalies in both axial and appendicular skeleton compared to the control group that having skeleton with normal size and shape, all the bones in a well-ossified condition stained red. The fetuses of the treated dams showed skeletal anomalies in the sternum, ribs, fore- and hind-limbs.

Concerning skeletal examination of alizarin red and alcian blue stained fetuses, the doses of meloxicam 1.35 and $2.70 \mathrm{mg}$. $\mathrm{kg}$ b.wt resulted in an incomplete ossification of the skull bones, vertebral column, and incomplete ossification of fore limb and, hind limb bones and pelvic girdle. (Fig.3)

\subsubsection{Oxidative stress observations}

Lipid peroxidase (Malonaldahyde MDA) is significantly increased in fetus obtained from pregnant rat given meloxicam at 1.35 and
$2.70 \mathrm{mg} / \mathrm{kg}$ b.wt. from the $6^{\text {th }}$ to the $15^{\text {th }}$ day of gestation when compared to normal control and control tween 80 groups. Reduced glutathione is significantly decreased in fetus obtained from pregnant rat given meloxicam at 1.35 and $2.70 \mathrm{mg} / \mathrm{kg} \mathrm{b.wt}$. from the 6th to the 15th day of gestation when compared to normal control and control tween 80 groups. (Fig 4)

3.1.6. Histopathological studies

Meloxicam at $1.35 \mathrm{mg} / \mathrm{kg}$ b.wt caused multiple megakaryblasts in the hepatic tissue with congestion in the hepatic sinusoids in liver of fetuses from pregnant female administered it from day 6th to day 15th of pregnancy. Fig (42) also caused swelling in the endothelial cells lining the tufts associated with degeneration in the tubular lining epithelium of the glomeruli of kidney.

Meloxicam at $2.70 \mathrm{mg} / \mathrm{kg}$ b.wt caused congestion in the central veins and sinusoids of liver of fetuses from pregnant female administered it from day 6th to day 15th of pregnancy. Fig (44). And caused necrosis in the tubular lining epithelium of kidney.(Fig 5)

Table (1) Effect of meloxicam (1.35 and $2.7 \mathrm{mg} / \mathrm{kg}$ b.wt.)On the abortion percent

\begin{tabular}{|c|c|c|c|c|}
\hline Group & $\begin{array}{c}\text { Doses } \\
\left.\text { (mg. } \mathrm{kg}^{-1} \mathrm{~b} . w \mathrm{t}\right)\end{array}$ & $\begin{array}{l}\text { No. of used } \\
\text { female }\end{array}$ & $\begin{array}{c}\text { No. of } \\
\text { abortion }\end{array}$ & $\begin{array}{c}\text { Abortion } \\
(\%)\end{array}$ \\
\hline Normal Control & $1 \mathrm{ml}$ water & 10 & 0 & \\
\hline Control tween ${ }^{80}$ & $1 \mathrm{ml}$ tween & 10 & 0 & \\
\hline Meloxicam & 1.35 & 10 & 1 & \\
\hline
\end{tabular}




$\begin{array}{ccccc} & \text { Number of } & \text { Number of } & \text { Viable } & \text { Resorbed } \\ \text { Groups } & \text { Doses } & \text { rats } & \text { Implantation } \\ \text { (mg.kg.wt) } & & \text { sites } & \text { fetuses } & \text { fetuses }\end{array}$

$1 \mathrm{ml} \quad 10 \quad 61$

Normal control

dist. water

$1 \mathrm{ml}$ tween 80

10

Control tween ${ }^{80}$

58

$57 \quad 98.2 \quad 1$

Meloxicam

49

46

$93.8 \quad 3$

6.12
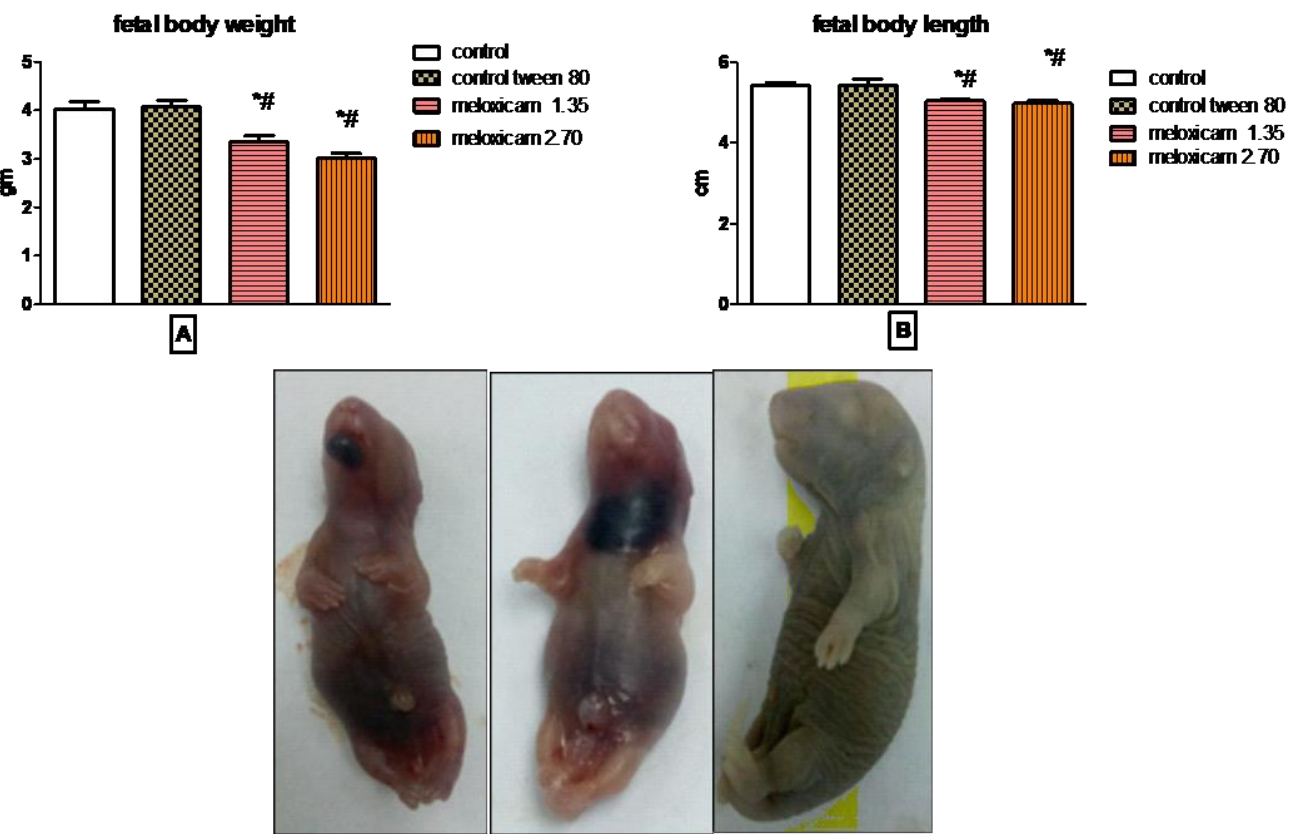

田

四

E

Fig. (1): A histogram showing effect of meloxicam on fetal body weight (A) and on the fetal body length of fetuses (B) maternally treated with 1.35 and $2.7 \mathrm{mg} / \mathrm{kg}$ from $6^{\text {th }}$ to $15^{\text {th }}$ day of gestation. and photograph of fetuses obtained from pregnant rats given meloxicam at 1.35 and $2.7 \mathrm{mg} / \mathrm{kg}$ b.wt from the $6^{\text {th }}$ to the $15^{\text {th }}$ day of gestation showing hematoma all over the body (C-D) and paralysis in fore limb (E) (Arrows). Data are expressed as mean \pm standard error of mean $(\mathrm{N}=6)$. The statistical differences were analyzed by ANOVA. *Significantly different from control and " significantly different from control tween 80 at $\mathrm{p}<0.05$ 

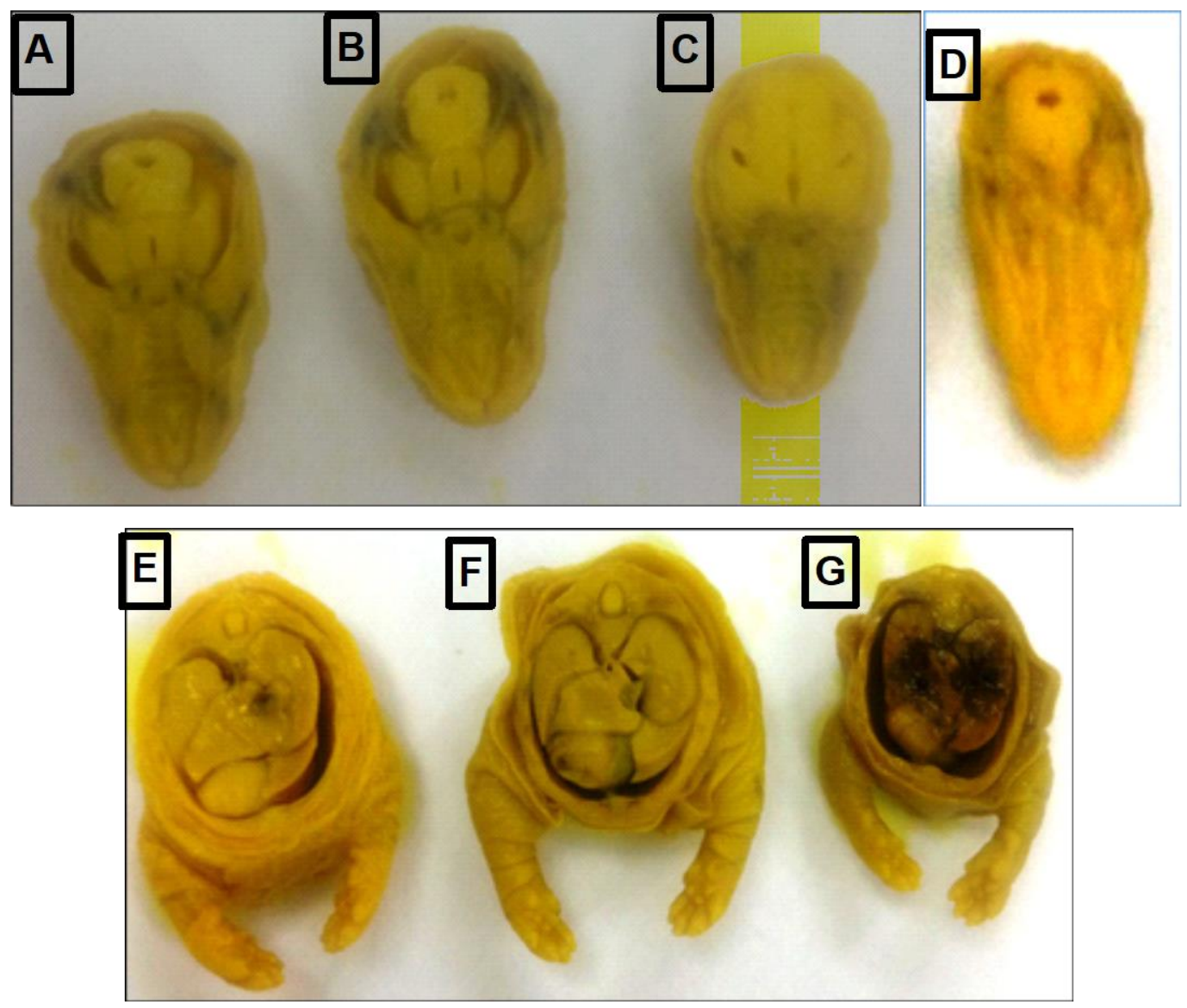

Fig. (2): photograph of brain showing cerebral dilatation of fetuses obtained from pregnant rats given $1.35 \mathrm{mg} / \mathrm{kg}$.wt. Meloxicam (C) and microcephaly of fetuses obtained from pregnant rats given $2.7 \mathrm{mg} / \mathrm{kg}$.wt. Meloxicam (D) from the $6^{\text {th }}$ to the $15^{\text {th }}$ day of gestation (Arrows) when compared to normal control and tween 80 groups (A, B). And hemorrhage all over the internal organs of fetus obtained from pregnant rats given $2.7 \mathrm{mg} / \mathrm{kg}$ - $1 \mathrm{~b}$.wt. Meloxicam from the $6^{\text {th }}$ to the $15^{\text {th }}$ day of gestation (Arrows) when compared to normal control and tween 80 groups (E, F). 

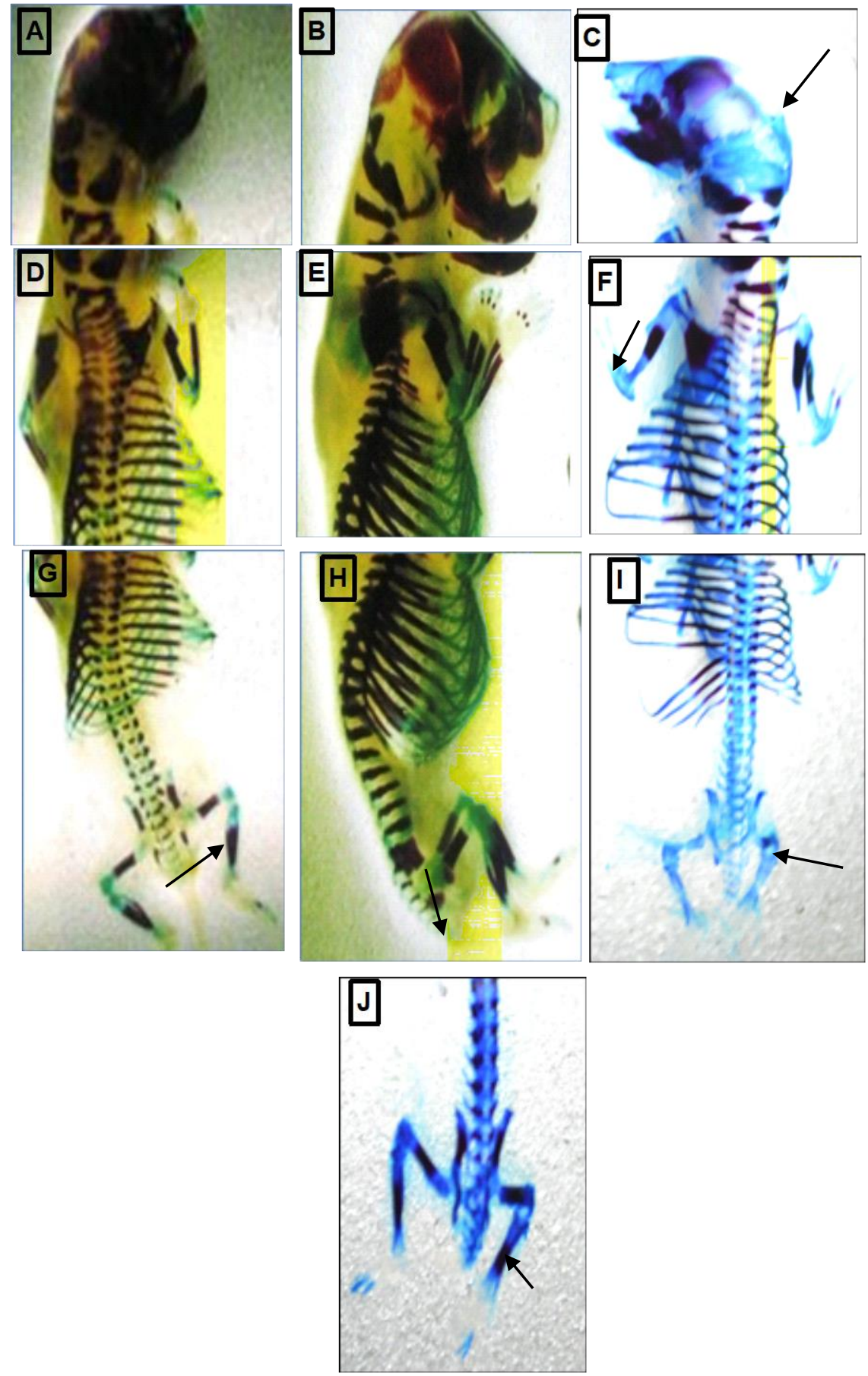

Fig. (3): Photograph of head of normal rat fetus (A), control tween 80 (B) and of fetus obtained from pregnant rat given $2.70 \mathrm{mg} / \mathrm{kg}-1 \mathrm{~b}$.wt. Meloxicam from the $6^{\text {th }}$ to the $15^{\text {th }}$ day of gestation showing lack of ossification (C). And photograph of fore limbs of normal rat fetus (D), of control tween 80 (E) and of fetus obtained from pregnant rat given $2.70 \mathrm{mg} / \mathrm{kg}$.wt. Meloxicam from the $6^{\text {th }}$ to the $15^{\text {th }}$ day of gestation showing lack of ossification of radius and ulna and complete lack of ossification of carpal and metacarpal bones (F) (Arrows). And photograph of hind limbs of normal rat fetus $(\mathrm{G})$, of control tween $80(\mathrm{H})$, of fetus obtained from pregnant rat given $2.70 \mathrm{mg} / \mathrm{kg}-1 \mathrm{~b} . \mathrm{wt}$. Meloxicam during period of organogenesis showing complete lack of ossification of vertebral column, femure, tibia, fibula, tarsal and metatarsal bones (I) and of fetus obtained from pregnant rat given $1.35 \mathrm{mg} / \mathrm{kg}-1 \mathrm{~b}$.wt. Meloxicam during period of organogenesis showing shortness of tibia and fibula ( $\mathrm{J})$ (Arrows). 


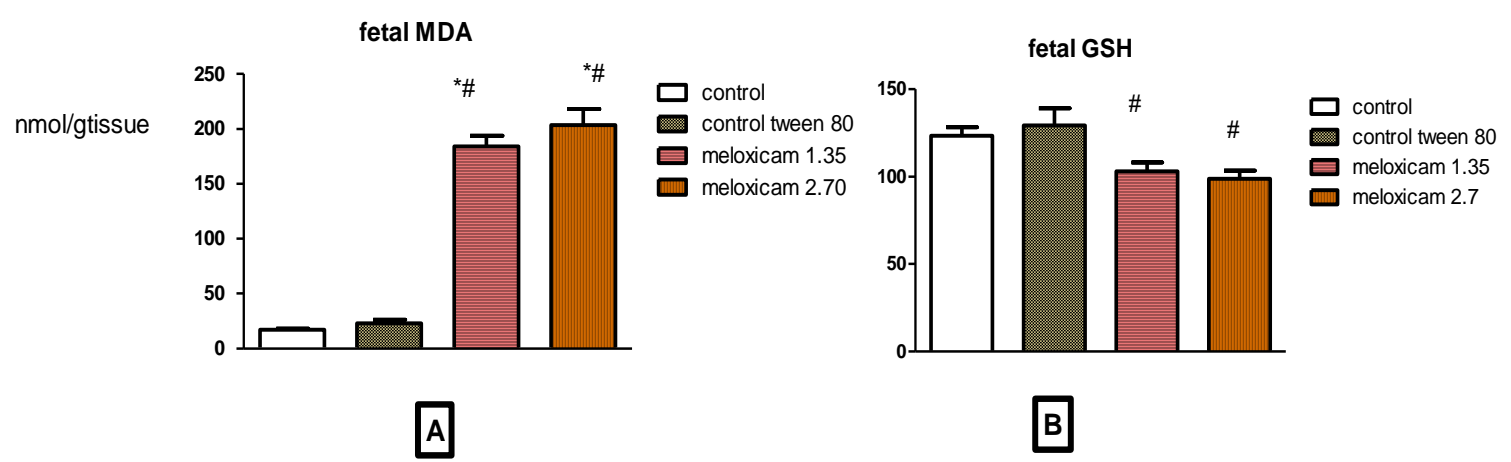

Fig. (4) A histogram showing effect of meloxicam on malonaldahyde (MDA)(A) glutathione (GSH)(B) of fetuses maternally treated with 1.35 and $2.70 \mathrm{mg} / \mathrm{kg}$ from $6^{\text {th }}$ to $15^{\text {th }}$ day of gestation. Data are expressed as mean \pm standard error of mean $(\mathrm{N}=6)$. The statistical differences were analyzed by ANOVA. *Significantly different from control and " significantly different from control tween 80 at $\mathrm{p}<0.05$.

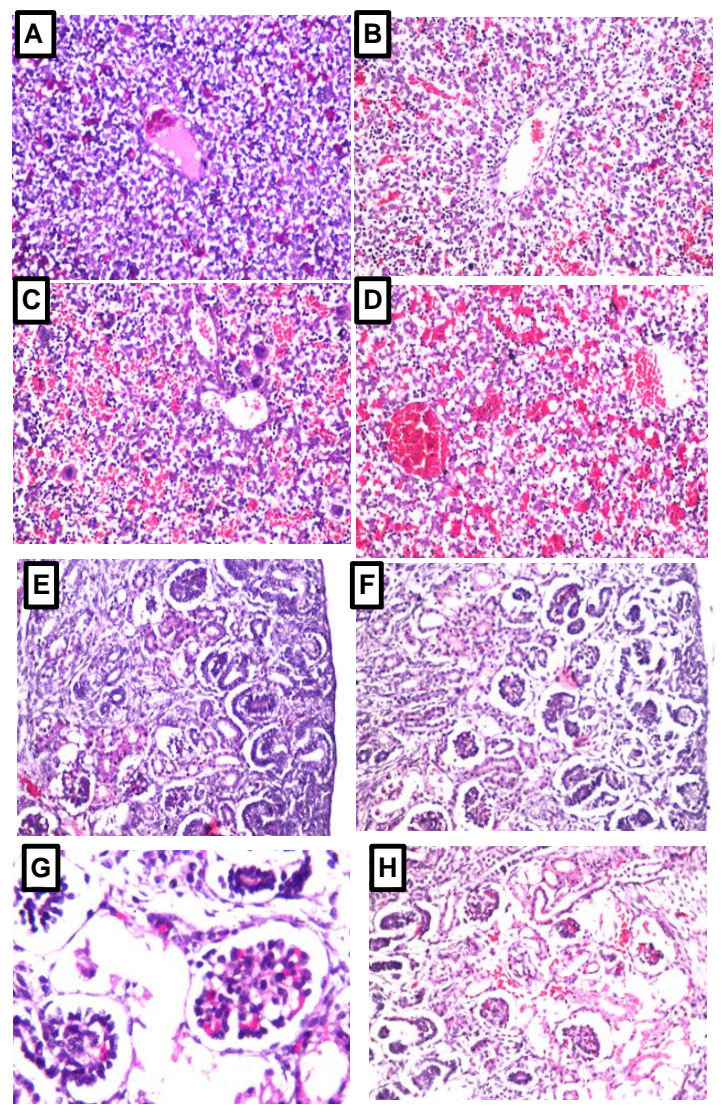

Fig. (5) photograph of liver of fetus from female received normal saline showing no histopathological alteration and the normal histological structure of the central vein and surrounding hepatocytes in the parenchyma(A),of fetus from female received tween 80 showing no histopathological alteration(B),of fetus from female received meloxicam at $1.35 \mathrm{mg} / \mathrm{kg}$ b.wt. Showing multiple megakaryblasts in the hepatic tissue with congestion in the hepatic sinusoids. (C).and of fetus from female received meloxicam at $2.70 \mathrm{mg} / \mathrm{kg}$ b.wt. Showing congestion in the central veins and sinusoids. (D) And of kidney of fetus from female received normal saline showing no histopathological alteration and the normal histological structure of the glomeruli and tubules at the cortex (E), of fetus from female received tween 80 showing no histopathological alteration .the normal histological structure of the glomeruli and tubules at the cortex were recorded in $(\mathrm{F})$, of kidney of fetus from female received meloxicam at $1.35 \mathrm{mg} / \mathrm{kg}$ b.wt. Showing swelling in the endothelial cells lining the tufts associated with degeneration in the tubular lining epithelium of the glomeruli. (G) And of kidney of fetus from female meloxicam at $2.70 \mathrm{mg} / \mathrm{kg}$ b.wt. Showing Necrosis in the tubular lining epithelium. (H). H\& E; $x 40$ 


\section{DISCUSSION}

Oral administration of meloxicam to pregnant rats increased the rate of abortion and the number of resorption sites. Meloxicam caused increase in number of resorptions sites and the number of implantation sites was significantly decreased in all treated groups (Sahar et al., 2006).

Oral administration of meloxicam caused growth retardation of fetuses revealed as body weight and length reduction. Previous studies mentioned similar results as intrauterine growth retardation was found in rats treated with the highest dose of piroxicam (Franciszek et al., 2005).In addition meloxicam caused significant retardation in weight, size and length of the maternally treated newborns was also detected compared to control (Gamal et al., 2011).In this study meloxicam resulted in cerebral dilatation, microcephaly and hemorrhage around internal organs. As Prenatal exposure to piroxicam increased the risk of ventricular septal and midline defects (Franciszek et al., 2005). Women prescribed NSAIDs as ibuprofen and meloxicam during early pregnancy may be at a greater risk of having children with congenital anomalies, specifically cardiac septal defects (Benjamin et al., 2006). Finally it is concluded that exposure to NSAIDs after 30 weeks' gestation is associated with an increased risk of premature closure of the fetal ductus arteriosus and oligohydramnios. Fetal and neonatal adverse effects affecting the brain, kidney, lung, skeleton, gastrointestinal tract and cardiovascular system have also been reported after prenatal exposure to NSAIDs (Roberto et al., 2012).In the present study meloxicam caused an incomplete ossification of the skull bones, sternbrae, vertebral column, forelimb bones, bones of hind limb and bones of pelvic griddle. As COX-2 inhibitors caused decrease of bone mineralization limited to various parts of axial skeleton and metacarpal bodies' and irregular partially mineralized cartilage "islet" was found in shaft of the humerus, ulna and femur (Franciszek et al., 2005). Nonselective COX inhibitors (ibuprofen, piroxicam, tolmetin) decreased alizarin staining, decreased vertebrae mineralization However, significant differences were noted only for the fifth and sixth lumbar vertebrae in the group exposed to the highest dose of tolmetin (Franciszek et al., 2008). Meloxicam, celecoxib and leflunomide caused a significant decrease in ossified lengths of certain axial and appendicular bones and evident missing of ossification centers were observed in the maternal treated litters (Gamal et al., 2011). In this study meloxicam caused multiple megakaryblasts in the hepatic tissue with congestion in the hepatic sinusoids in liver of fetuses from pregnant female administered it from day $6^{\text {th }}$ to day $15^{\text {th }}$ of pregnancy also caused congestion in the central veins and sinusoids. These data supported by that daily treatment by mefenamic acid caused marked histopathological changes with inflammation and mild hepatocellular necrosis and an increase in liver weight (Somchit et al., 2004). Mechanism by which non-steroidal anti-inflammatory agents caused hepatotoxicity suggested by who told that NSAIDs such as diclofenac, sulindac and ibuprofen are capable of producing protein adducts that may be a key process in the pathogenesis of NSAID induced liver injury (Wade et al., 1997). Meloxicam also caused swelling in the endothelial cells lining the tufts associated with degeneration in the tubular lining epithelium of the glomeruli of kidney and necrosis in the tubular lining epithelium of kidney. Utero exposure to (NSAIAs) can produce combinations of acute or chronic renal injury. NSAIAs induce renal 
dysgenesis in fetal monkeys and renal structural abnormalities in the developing human fetus. It is possible that the histopathological findings of uncertain or incomplete tubular differentiation may be the result of a direct effect of NSAIAs on developing or "immature" tubules (Bernard et al., 1994).

\section{FOOTNOTES}

\section{CONFLICT OF INTEREST}

The authors declare that they have no financial or personal conflicts of interest that influenced or could be perceived to have influenced this work.

\section{ACKNOWLEDGMENTS}

The authors would like to thank Prof. Adel Bakear (Pathology Department, Faculty of Veterinary Medicine, Cairo University,Cairo, Egypt for his assistance in the histopathological examinations.

\section{REFERENCES}

Ahmet, C.;Ahmet, C.; Kvanç, T. ;Mehmet, N. D.;Hakan, S.U.B.;Ahmet, S. U.;Mehmet, S.; and Seda, H.V.(2010):

The Effects of Meloxicam on Neural Tube Development.Turkish Neurosurgery, 20(2): 111-116.

Antonucci, R.; Marco Zaffanello;Puxeddu Elisabetta ; Annalisa Porcella;Laura Cuzzolin; and Maria.( 2012):

Use of Non-steroidal Antiinflammatory Drugs in Pregnancy: Impact on the fetus and Newborn. American journal of clinical pathology. Current Drug Metabolism,.

Banchroft , J.D.; Stevens , A. And Turner, D.R. (1996):

Theory and practice of histological teqniques.

Fourth Ed. Churchil Livingstone ,New York, London, San Francisco, Tokyo. Barcellona, P.S.; Fancelli, O.; and Campana, A. (1977):
TeratologicaI study of etoperidone in the rat and rabbit. Toxicology. 1977; 8:87-94.

Benjamin, O.; Driss, O.; Lucie, B.; Evelyne, R.; and Anick, Be. (2006):

Risk of Congenital Anomalies in Pregnant Users of Non-Steroidal AntiInflammatory Drugs: A Nested CaseControl Study.Birth Defects Research; 77:268-279.

Bernard, S. Kaplan.; Irene, Restrain. Devyani, S. RavaP.; Ruth, P. Gottlieb.; and Jay, Bernstein. Renal failure in the neonate associated with in utero exposure to nonsteroidal anti-inflammatory agents. Pediatric Nephrology 1994; 8: 700- 704.

Beutler, E.; Duron, O.; and Kelly, B.M . (1963):

Improved method for the determination of blood glutathione. Journal of Laboratory and Clinical Medicine; 61:882-8.

Franciszek, B. (2005):

Comparison of developmental toxicity of selective and non-selective cyclooxygenase- 2 inhibitors in CRL :( WI) WUBR Wistar rats - DFU and piroxicam study. Toxicology; 211:1225 .

Franciszek, B.;Justyna, S.; Barbara, M.; Robert, K.; and Jaroslaw,D.( 2005):

Skeletal developmental effects of selective and nonselective cyclooxygenase-2 inhibitors administered through organogenesis and fetogenesis in Wistar CRL:(WI)WUBR rats. Toxicology; 216: 204-223.

Franciszek, B.; Rozylo, K.I.b.;Szumilo, J.c.; Dudka, J.c.; and Klepacz, R.( 2008):

Cyclooxygenase Inhibitors Affect Bone Mineralization in Rat Fetuses. Cells Tissues Organs.; 187:221-232. 
Gamal, M. B.;Hassan, I. E.; and Eman, E. A. (2011):

Maternal and Neonatal Toxicities induced by three Antirheumatic Drugs in Albino Rats. Journal of American Science; 7(6).

Hayes, A.W. (1986):

Principles and Methods of Toxicology.

Student Edition, Raven Press, New York, 141-184.

Institute of Laboratory Animal Resources. Guide for the Care and Use of Laboratory Animals, 8th edition. Washington, D.C.:

National Academy Press; (1996):

Inouye, M. (1976):

Differential staining of cartilage and bone in fetal mouse skeleton by Alcian blue and Alizarin red-S .congenital Anomalies; 16: 171-173.

Maria, A. A.; Etienne, N.; Enrique, M. O.; and Ganesh, K. (2001):

Analysis of Nonsteroidal Antiinflammatory Drugs in Meconium and Its Relation to Persistent Pulmonary Hypertension of the Newborn. PEDIATRICS, 107:519-523.

Paget, G.E. and Barnes, I.M. (1964):

Interspecies dosage conversion scheme in evaluation of results and quantitative application in different species in (evaluation of drug activities:Pharmacometrics).

Laurance, D.R. and Bachorach, A.L. (Edrs), Academic Press London and New York. ; 1: 160-163.

Qstensen, M.E.; and Skomsvoll, J.F. (2004):

Anti-inflammatory pharmacotherapy during pregnancy.Expert Opinion on Pharmacotherapy.; 5, 571-580.

Sahar, M. J.; Abdulazim, S. S.; Ahmad, M. D.; and Farouq A. (2006):

Effects of Meloxicam on Implantation and Parturition of Rat. $\mathbf{J}$ Medical Journal; 40 (2): 88- 95.
Schardein, L.J. (1977):

Drugs as teratogens . C.R.C Press, Inc.

Ohio, U.S .A.

Somchit, N.; Sanat, F.; Gan, E. H.; Shahrin, I

.A .W. and Zuraini, A. (2004):

Liver injury induced by the non-steroidal anti-inflammatory drug mefenamic acid. Singapore Medical Journal; 45(11): 530.

Uchiyama.M.; and Mihara M. (1978):

Analytical biochemistry. 86, 271

Urban, M. (2000):

Cox-2 specific inhibitors offer improved advantages over traditional NSAIDs. Orthopedis; 23:61-64.

Wade L.T, Kenna J.G and Caldwell J. (1997):

Immunochemical identification of mouse hepatic protein adducts derived from the nonsteroidal anti-inflammatory drugs diclofenac, sulindac, and ibuprofen. Chemical Research Toxicology.; 10:546-55.

Zenker, M.;Klinge, J.; Kruger, C.; Singer, H.; and Scharf, J. (1998):

Severe pulmonary hypertension in a neonate caused by premature closure of the ductus arteriosus following maternal treatment with diclofenac: a case report Journal of Perinatal Medicine. , 26(3):231-234. 